\title{
Experimental investigation of three different tube equal channel angular pressing techniques
}

\author{
F. Djavanroodi ${ }^{1,2 *}$, A. A. Zolfaghari ${ }^{1}$, M. Ebrahimi ${ }^{1}$ \\ ${ }^{1}$ Department of Mechanical Engineering, Iran University of Science and Technology, Tehran, Iran \\ ${ }^{2}$ Department of Mechanical Engineering, Prince Mohammad Bin Fahd University, Al Khobar, Saudi Arabia
}

Received 10 March 2013, received in revised form 9 December 2013, accepted 27 May 2014

\begin{abstract}
Three methods to fabricate ultra fine grain tube shaped specimens have been proposed and tested using conventional equal channel angular pressing (ECAP) die with the channel angle of $90^{\circ}$. Commercial pure copper tubes have been put through up to three passes via route C. Sand (S-ECAP), rubber (R-ECAP) and grease (G-ECAP) were used as a mandrel to maintain tubularity of samples during deformation processes. Hardness values and thickness variations of the deformed tubes were measured and compared for the above three techniques. To confirm the reduction of grain size, the microstructures of the copper tube before and after equal channel angular pressing were also examined using optical and scanning electron microscopy. The results imply that although all three tube production methods lead to the improvement of hardness magnitudes, R-ECAPed and G-ECAPed tube samples give higher hardness magnitude and better hardness distribution uniformity, respectively. Furthermore, the outcomes denote that R-ECAP gives the least tube wall thickness changes as compared to S-ECAP and G-ECAP processes.
\end{abstract}

Ke y words: severe plastic deformation (SPD), equal channel angular pressing (ECAP), tube, hardness behavior, thickness measurement

\section{Introduction}

In the last two decades, numerous studies have been carried out on physical, mechanical, superplastic, wear and corrosion properties [1-3] of ultra-fine grained (UFG) and nano-structured (NS) metals and alloys. These materials can be fabricated using two different methods. In the first one called the bottom-up approach, the NS sample is produced through atom by atom and layer by layer arrangements and also, by consolidation of nanoparticle solids. This type has not been welcomed by industrial applications, because of the final porous structure and small dimensional size. On the other hand, the second method to fabricate UFG materials is a top-down approach. During this process, microstructure is changed to the UFG structure by severe plastic deformation (SPD) techniques. The fabricated materials using the SPD techniques are of great interest since the fabrication difficulties associated with the first method are overcome. The method effectively gives a uniformly dense structure and allows for relatively large quantity production for industrial operations $[4,5]$.

Since the early studies, many more SPD processing techniques have been proposed, developed and investigated. These include equal channel angular pressing [6], high pressure torsion [2], twist extrusion [7], accumulative roll bonding $[8]$ and constrained groove pressing [9]. The fundamental principle of all SPD methods is the same. In general, a lot of dislocations are generated because of intense shear deformation of specimen. Then, dislocation walls appear due to accumulating and combining. In the next step, transformation of dislocation walls into low angle grain boundaries (LAGBs) takes place and finally, these subgrains change into high angle grain boundaries (HAGBs). With this method, equiaxed ultra-fine grains are constructed during all SPD processes [1-5].

Among various SPD techniques, equal channel angular pressing (ECAP) is the most famous method,

*Corresponding author: e-mail address: fdjavanroodi@pmu.edu.sa 
because of feasible and low cost die design set-up. This process was initially proposed and experimentally treated by Segal et al., and then, developed by Valiev and Langdon. During one pass equal channel angular pressing process, the billet is pressed through the inlet channel via a punch. Then, a large plastic strain is imposed to the sample when it passes through the shear plane at the intersection of the inlet and outlet channels. The magnitude of strain during one pass process depends on the die channel and outer corner angles in the frictionless condition. Repetitive pressings are possible to accumulate high level plastic strain magnitude in the specimen without any substantial alteration at the initial dimension of deformed work-piece $[4,10,11]$. Although equal channel angular pressing process had been originally applied to bulk shaped materials, development and modification of this method to produce wire [12], plate [4], and even tube shaped samples [13] are reported.

There are few SPD methods developed for fabrication of UFG tube and hollow shaped materials in spite of high demands by aerospace, automobile and petroleum industries. These techniques consist of spin extrusion (SE), high pressure tube twisting (HPTT), and accumulative spin bonding (ASB). Spin extrusion is recognized as an incremental rotating forming process, which is the combination of flow turning and backward extrusion technologies. The principle of SE process is that the cylindrical billet is clamped in a chuck and rotates around its own longitudinal axis. The forming mandrel, as well as the three rollers, are simultaneously subjected to the axial feed, see Fig. 1a. It is noted that the rotating movements of forming mandrel and rollers result from the frictional effect. The hollow shaped, and even internally profiled specimens are produced via flowing off axially opposite to the feed direction by these two implements $[14,15]$. Another process to fabricate UFG tube is the high pressure tube twisting technique. In HPTT method generated by Toth et al. [16], tube formed sample is positioned inside a rigid disk. A mandrel is located inside the tube, which is elastically compressed in the axial direction, and so, it expands gradually in the radial direction. The tube shaped work-piece is then constrained via a compression force on its upper and lower wall surfaces. Large hydrostatic stress is created in the tube, because of confining of mandrel expansion by means of the tube and disk. This hydrostatic stress provides a large friction force on both sides of the tube. Finally, high level plastic strain tube is obtained by rotating the rigid disk with an external torque while keeping the mandrel fixed $[16,17]$. The schematic representation of this technique is illustrated in Fig. 1b. Accumulative spin bonding, which is invented by Mohebbi and Akbarzadeh, is based on the cold bonding process; see Fig. 1c. In this process, two tubes are located inside each other, and then clamped on a rotating
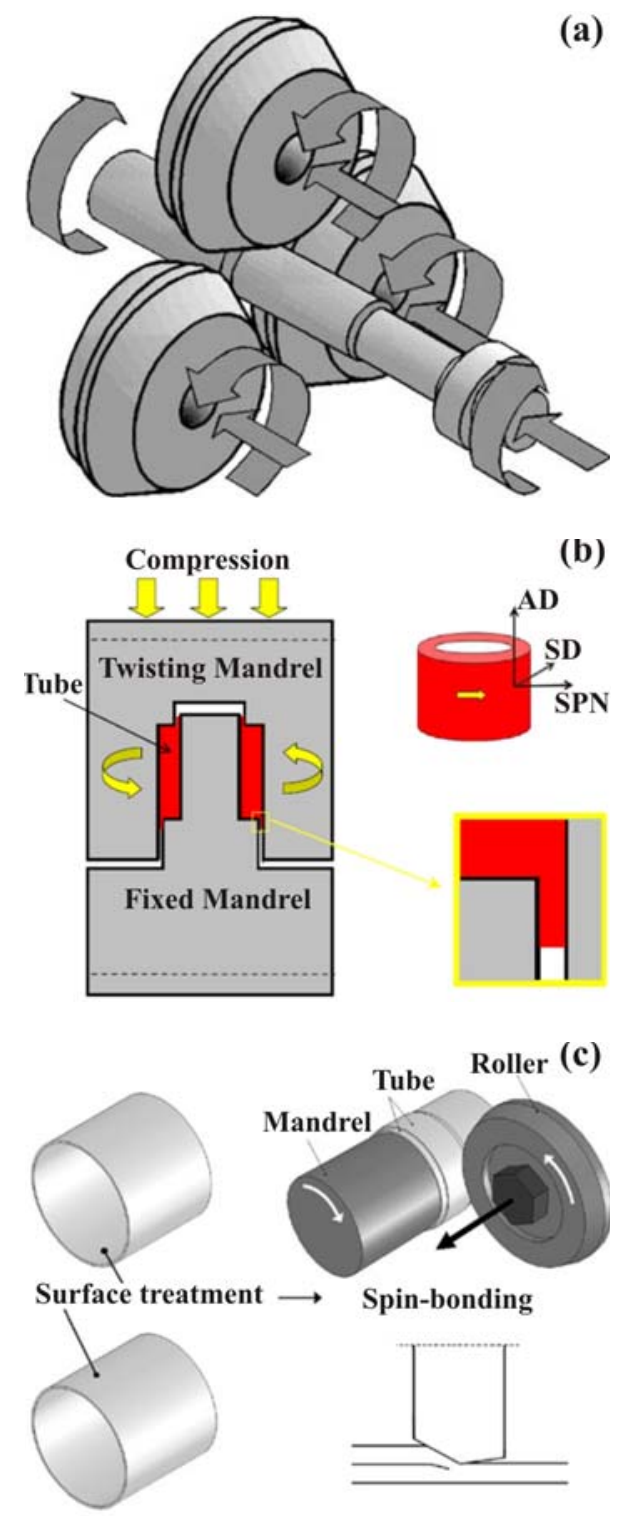

Fig. 1. The schematic representation of spin extrusion (a), high pressure tube twisting (b) and accumulative spin bonding (c) processes [15, 16, 18].

mandrel. Next, a roller moves axially along the direction of the tube axis. This operation is performed to decrease tube thickness by $50 \%[18,19]$. The techniques which have been considered are difficult and expensive in the die design set-up and operation and also, high magnitudes of processing variations are seen in these techniques, and hence, it can be said that they are not easily adapted for the fabrication and employment in large scale industrial applications and constructions.

Beside the above three methods of UFG tube fabrication, Zangiabadi and Kazeminezhad have proposed and investigated a new method of SPD processes based on the equal channel angular pressing 


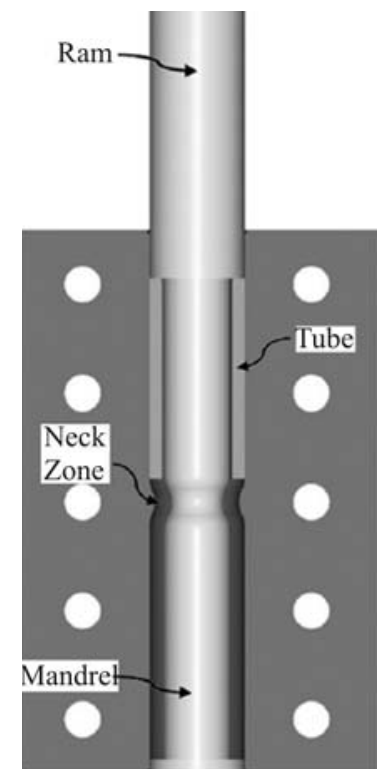

Fig. 2. The schematic representation of tubular channel pressing method [20].

conception named tubular channel pressing (TCP) $[20,21]$. The schematic representation of this technique is shown in Fig. 2. The principle of the TCP process is based on the pressing of tube shaped sample through the channel with a neck zone. A mandrel is applied inside the tube specimen to maintain tubularity of work-piece during deformation and prevent wrinkling. After one pass pressing, the punch is pulled out and the whole die set-up is vertically rotated by $180^{\circ}$, and then, the second pass is carried out in the same manner. In addition, three shear events take place during one pass of TCP process. It can be found that this method is more feasible and suitable than the above three techniques (SE, HPTT and ASB processes). It is very reasonable, attractive and idealistic if tube formed samples can be subjected to high plastic strain using conventional equal channel angular pressing die. By this way, conventional die can be utilized for both bulk and tube shaped work-pieces.

In this research, three techniques have been proposed to fabricate tube samples using conventional equal channel angular pressing die, and examined experimentally. The sand, rubber and grease were employed as a mandrel to keep tubularity of specimens. Furthermore, the microstructures and experimental investigations of the specimen before and after final process were examined using optical and scanning electron microscopy. Finally, hardness behavior and tube wall thickness variations of equal channel angular pressing tube specimens have been measured and compared.

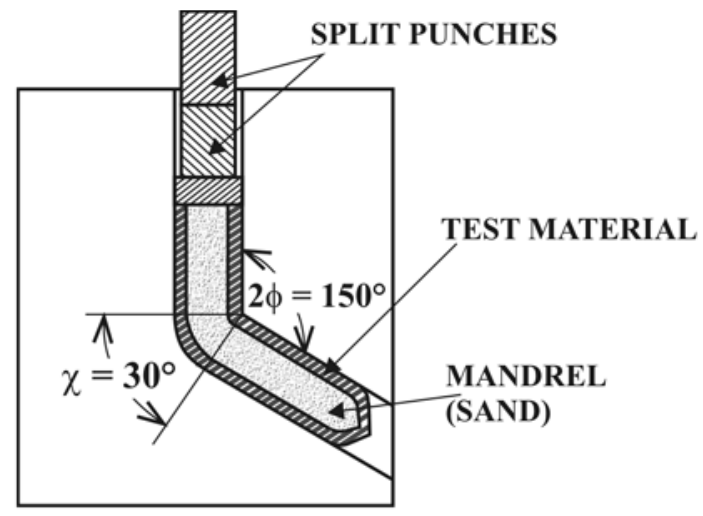

Fig. 3. The schematic representation of equal channel angular pressing tube using sand [22].

\section{ECAP process of tube shaped materials}

The main concern during equal channel angular pressing process of tube shape specimen is to prevent tubes from crushing (i.e., maintaining the tubularity of the specimens during the process). To retain the tube shape, sand, rubber and grease were inserted inside the tube specimens as a mandrel. These methods are referred as S-ECAP, R-ECAP and G-ECAP, respectively. Pressing of tube samples using sand was initially proposed and introduced by Nagasekhar et al. $[13]$ on the aluminum alloy; see Fig. $3[13,22]$. The results indicate that improvement of mechanical properties can be achieved via S-ECAP method, whilst sand ensures shape retention of specimens. Also, theoretical and experimental investigations showed that this process required low pressing force due to the fact that the drag friction (exerted by the sand) acted in the same direction with the main punch force.

In this paper, equal channel angular pressing of commercial purity copper tube specimens had been carried out using sand, rubber and grease as the mandrel. All three types were pressed up to three passes by route $\mathrm{C}$ in which the sample was rotated by $180^{\circ}$ around its longitudinal axis between each consecutive passes. Then, the influence of mandrel types on the hardness behavior and tube thickness variations of deformed copper tubes was studied.

\section{Experimental procedure}

The experiments were conducted with commercial purity $(\mathrm{CP})$ copper in the shape of hollow specimens. Tube samples with outer diameter of $19 \mathrm{~mm}$, thickness of $3.5 \mathrm{~mm}$ and length of $140 \mathrm{~mm}$ were used for the experimental work. It is noted that for S-ECAP and G-ECAP one end of the tube samples was sealed to avoid the loss of mandrels (sand and grease). The tube work-pieces were annealed at $500^{\circ} \mathrm{C}$ for $1 \mathrm{~h}$, and 
Table 1. Mechanical properties of the polyurethane pad [23]

\begin{tabular}{cccc}
\hline Hardness shore & M-R Constant $C_{01}(\mathrm{MPa})$ & M-R Constant $C_{10}(\mathrm{MPa})$ & Poisson's ratio $\nu$ \\
\hline 90 & 0.969 & 0.393 & 0.4999 \\
\hline
\end{tabular}

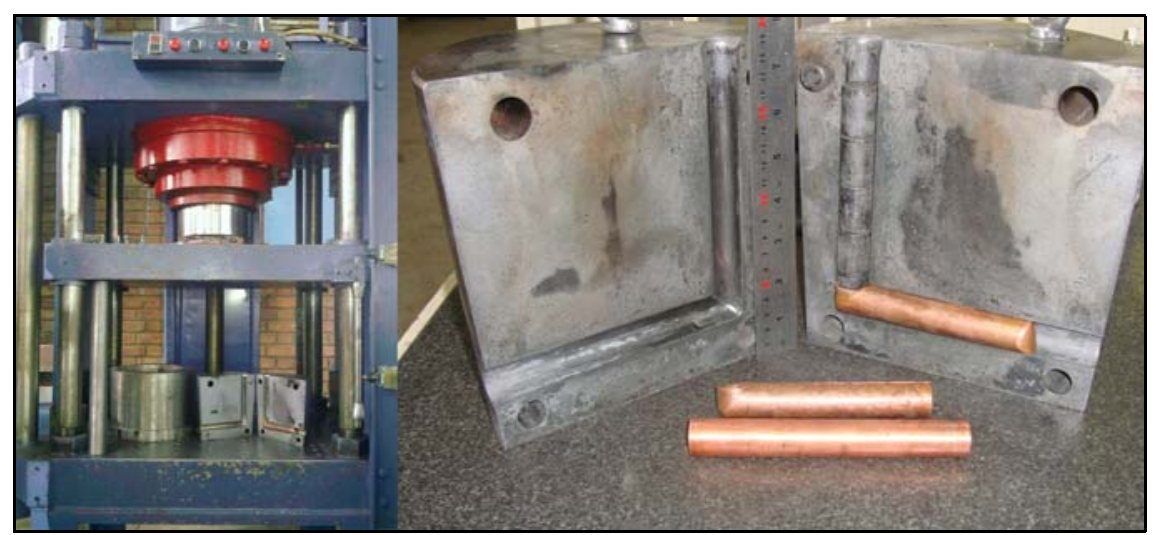

Fig. 4. Hydraulic press, equal channel angular pressing die set-up and $\mathrm{CP} \mathrm{Cu}$ tube specimens before and after pressing.

then, furnace cooled. Rounded sand with the grain size of about $1 \mathrm{~mm}$ was prepared for the configuration of S-ECAP process. Flexible polyurethane rubber with mechanical properties listed in Table 1 [23] was fitted as a mandrel inside the copper tube work-pieces for the condition of R-ECAP, and finally, general purpose grease was chosen for the G-ECAP process. To ECAP the copper tubes die with the channel angle of $90^{\circ}$, outer corner angle of about $15^{\circ}$ and channel diameter of $19.1 \mathrm{~mm}$ was designed and manufactured. In addition, five separate short length punches were utilized to avoid buckling of punches during process. All equal channel angular pressing tests were carried out using molybdenum disulfide $\left(\mathrm{MoS}_{2}\right)$ as a lubricant to decrease frictional influences between the die and outer surface of the tube. Equal channel angular pressing process was performed at room temperature using hydraulic press with a ram speed of $1.5 \mathrm{~mm} \mathrm{~s}^{-1}$. Figure 4 represents hydraulic press, ECAP die set-up and tube samples before and after operation.

Copper tube specimens were pressed up to three passes by route $\mathrm{C}$ using three different mandrels: sand, rubber and grease. Then, Vickers micro hardness measurements were recorded for both un-ECAPed and ECAPed conditions with a load of $50 \mathrm{gf}$ (gram-force) for a dwell time of $15 \mathrm{~s}$ in the transverse direction (perpendicular to pressing direction). Also, tube thickness variation measurements were carried out using the tube thickness gauge to determine the best mandrel type for keeping tubularity of specimens. Furthermore, microstructure evaluation via SEM and optical microscopy $(\mathrm{OM})$ was employed to confirm refinement of the grain size during equal channel angular pressing process.

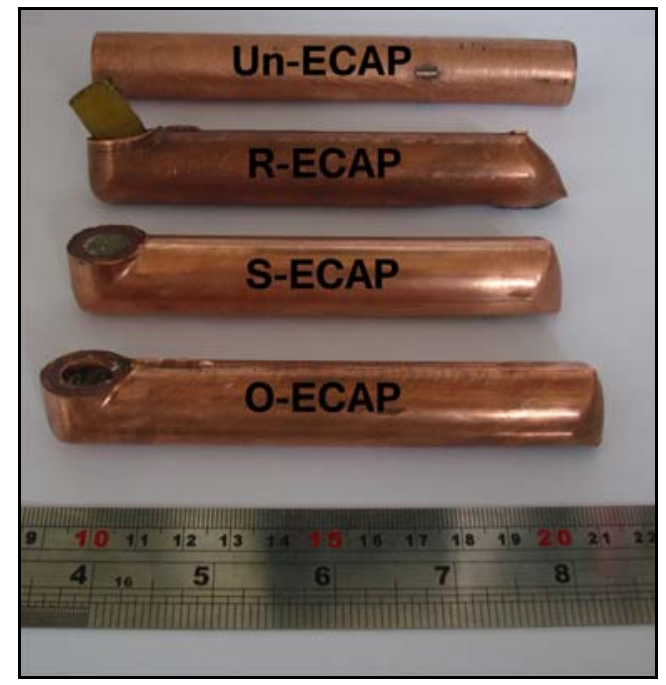

Fig. 5. Copper tube specimens before and after equal channel angular pressing process using sand, rubber and grease mandrels.

\section{Results and discussion}

Figure 5 represents copper tube samples after equal channel angular pressing process by sand, rubber and grease mandrels using die with the channel angle of $90^{\circ}$, outer corner of $15^{\circ}$ and channel diameter of $19.1 \mathrm{~mm}$. One of the shortcomings of this process is that the samples become shorter with increasing number of passes. This defect is related to the nature of this process and it cannot be avoided. For lubrication and fitting purposes the diameter of the die channel is greater than the sample diameters (in the ex- 
perimental setup, ECAP die channel and sample diameters were 19.1 and $19 \mathrm{~mm}$, respectively). Assuming volume constancy and also, constant tube wall thickness during the process, the tube shortens by approximately $3 \%$ at each pass. In addition, ECAPed specimens are machined after each pass to retain their initial diameter $(19 \mathrm{~mm})$ for further pressings. Therefore, ECAPed specimens with higher number of passes are expected to be shorter than those with lower number of passes.

\subsection{Hardness evaluation}

To investigate the hardness magnitude and hardness distribution homogeneity, Vickers micro hardness tests were carried out on the un-ECAPed, S-ECAPed, R-ECAPed and G-ECAPed configurations after the first and third passes of pressing. Three transversal planes with the space of $30 \mathrm{~mm}$ from the middle of sample's length have been used for HV recording of each method as shown in Fig. 6. A total number of 27 Vickers hardness measurements were recorded for each sample at the various points on the top, bottom and lateral regions. In all, $189 \mathrm{HV}$ tests were taken for this study.

Also, hardness distribution factor (HDF) was utilized to examine hardness distribution uniformity according to Eq. (1):

$$
\mathrm{HDF}=\frac{\sqrt{\frac{1}{n-1} \sum_{i=1}^{n}\left(\mathrm{HV}_{i}-\mathrm{HV}_{\mathrm{ave}}\right)^{2}}}{\mathrm{HV}_{\mathrm{ave}}}
$$

where $\mathrm{HV}_{i}$ is the Vickers hardness magnitude at each point, $\mathrm{HV}_{\text {ave }}$ is the average magnitude of Vickers hardness measurements, and $n$ is the number of data. Equation (1) takes the all HV magnitudes into consideration, therefore it is assessed that the HDF is a more suitable and satisfactory way for evaluating the hardness distribution homogeneity level within the tube. In

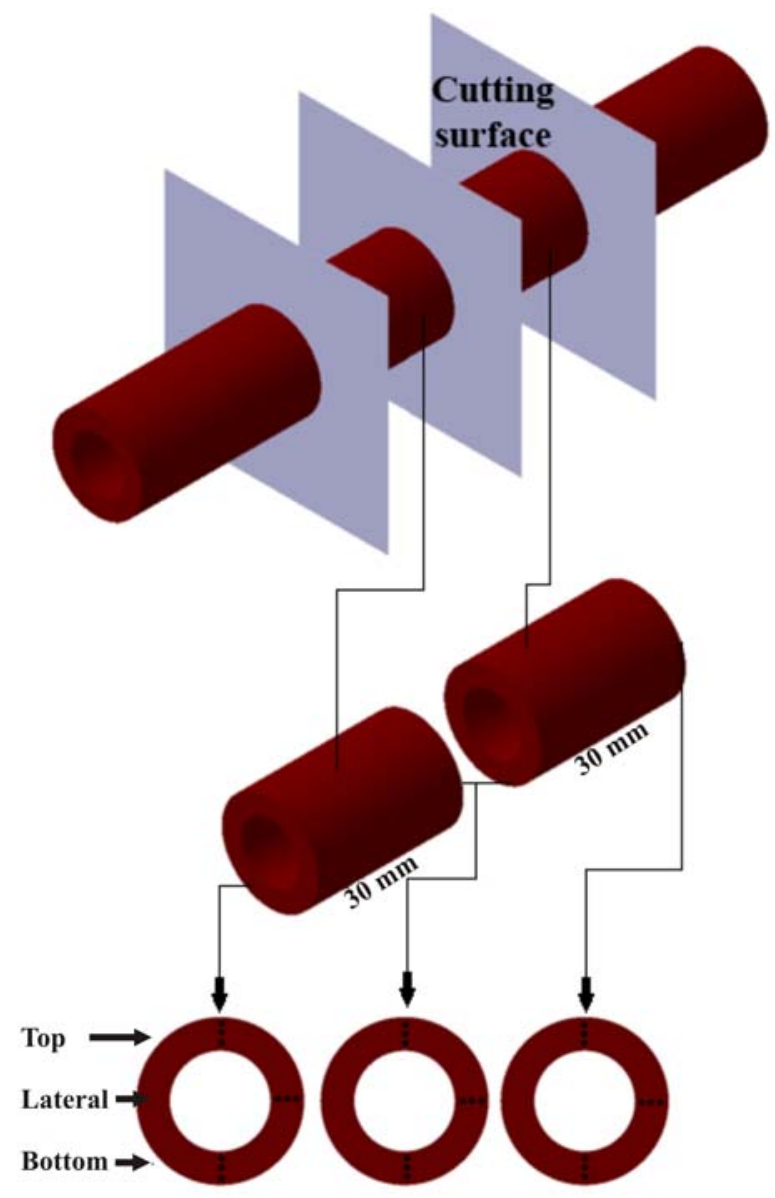

Fig. 6. The locations of Vickers hardness (HV) test for each sample.

addition, lower value for HDF indicates more uniform hardness distribution for that case.

Table 2 lists average hardness magnitude (HV) and hardness distribution factor (HDF) for the unECAPed, first and third passes of $\mathrm{Cu}$ ECAPed tube samples by sand, rubber and grease mandrels using route $\mathrm{C}$. As can be observed, the as-received state

Table 2. Magnitudes of Vickers hardness (HV) and hardness distribution factor (HDF) for the as-received, first and third passes of copper equal channel angular pressing tube specimens using sand, rubber and grease mandrels by route $\mathrm{C}$

\begin{tabular}{lccl}
\hline Pass & Condition & HV & HDF \\
\hline Un-ECAP & Annealing & 91 & 0.01 \\
\hline \multirow{3}{*}{ First } & Sand & 118.2 & 0.0310 \\
& Rubber & 120 & 0.0363 \\
& Grease & 117.7 & 0.0292 \\
\hline \multirow{3}{*}{ Third } & Sand & 132.1 & 0.0421 \\
& Rubber & 136.4 & 0.0503 \\
\hline
\end{tabular}



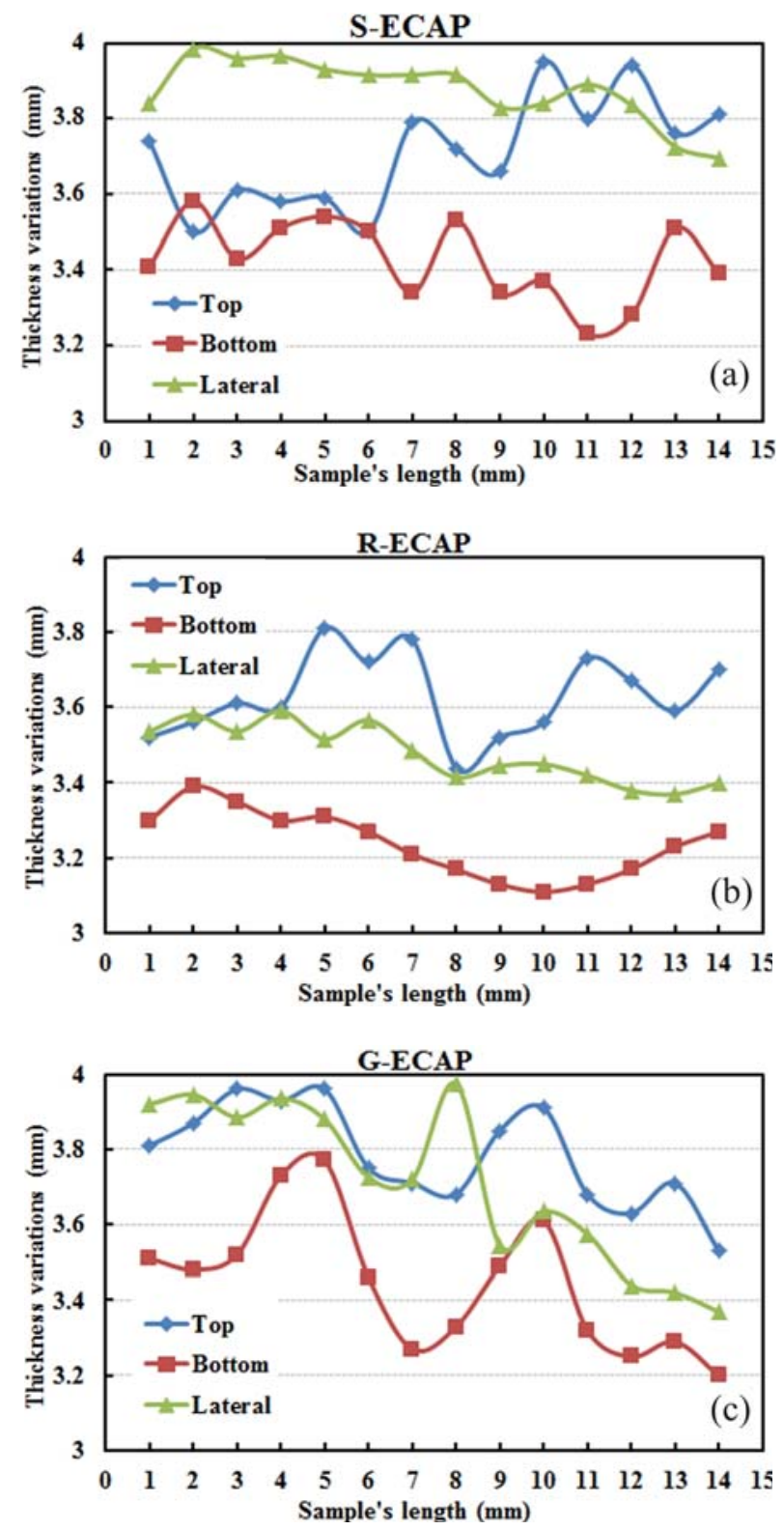

Fig. 7. Equal channel angular pressing tube thickness variations along sample's length at the various top, bottom and lateral regions after third pass pressings by route $\mathrm{C}$ using sand (a), rubber (b) and grease (c) mandrels.

of material which was treated by annealing process possesses HV value of $91 \mathrm{HV}$ with the HDF of 0.01 . After one pass equal channel angular pressing process, significant hardness enhancement was achieved in the tube materials irrespective of the mandrel type. The hardness magnitude improvements are about 30, 32 and $29 \%$ for deformed S-ECAPed, R-ECAPed and G-ECAPed work-pieces; respectively, as compared to the un-ECAPed condition. This hardness behavior amendment has been accompanied with the tensile properties and all these events are due to grain size refinements. Subsequent passes up to three passes by route $\mathrm{C}$ lead to increasing at the $\mathrm{HV}$ magnitudes up to 45,50 and $44 \%$ for the S-ECAPed, R-ECAPed and G-ECAPed tubes when compared with the as-received condition, respectively.

On the other hand, for the $1^{\text {st }}$ pass, the hardness distribution factor (HDF) increased by 210, 260 and $192 \%$ for S-ECAPed, R-ECAPed and G-ECAPed work-pieces; respectively, as compared to the unECAPed condition. This indicates that hardness distribution homogeneity decreased and there is a loss of axial symmetry in the properties of the tube due to un-symmetrical shear process acting on the tube. Subsequent passes up to three passes lead to increasing at the HDF magnitudes up to 321,403 and $255 \%$ for the S-ECAPed, R-ECAPed and G-ECAPed tubes comparing with the as-received condition, respectively. The G-ECAPed tube shows the best hardness distribution homogeneity. It is noted that the rubber pad and grease mandrels ECAPed tube sample gives the highest HV value and uniform hardness distribution, respectively.

\subsection{Tube wall thickness variation evaluation}

To determine tube wall thickness variations, the tube thickness gauge was utilized with direct range of measurement from 0 to $10 \mathrm{~mm}$ and 0.01 per unit. Tube wall thickness measurements were recorded for the third pass copper ECAPed tubes using different mandrels, see Fig. $7 \mathrm{a}-\mathrm{c}$. In fact, 45 different points along a sample's length with an equal distance from each other were recorded at various top, bottom and lateral regions of each configuration after removing head and tail parts of the specimens.

As can be observed, tube wall thickness variations at the top, bottom and lateral locations differ from each other for all three techniques. Generally, it is understood from Fig. 7 that tube wall thickness in the bottom region of all three S-ECAPed, R-ECAPed and G-ECAPed specimens is lower than in the top and lateral zones. This can be illustrated by the dead zone phenomenon which occurs at the outer corner of ECAPed die. The average magnitude and distribution of tube thickness were calculated for all three techniques. Equation (1) was used to calculate the tube wall thickness distribution; named thickness distribution factor (TDF). The results are listed in Table 3. As can be observed, the average tube wall thickness close to the un-ECAPed state belongs to the rubber pad technique. Also, in the longitudinal direction R-ECAP method leads to the most uniform thickness distribution axis of deformed material. Hence, rubber pad equal channel angular pressing technique results in a better average tube wall thickness and more uniform distribution of thickness than the other two methods.

From the results, it can be summarized that although G-ECAP configuration leads to better hard- 
Ta b l e 3. Magnitudes of average copper tube wall thickness (TT) and thickness distribution factor (TDF) after three passes of equal channel angular pressing by route $\mathrm{C}$ using sand, rubber and grease mandrels

\begin{tabular}{lccc}
\hline & S-ECAP & R-ECAP & G-ECAP \\
\hline TT & 3.67 & 3.45 & 3.65 \\
TDF & 0.0595 & 0.0539 & 0.0626 \\
\hline
\end{tabular}
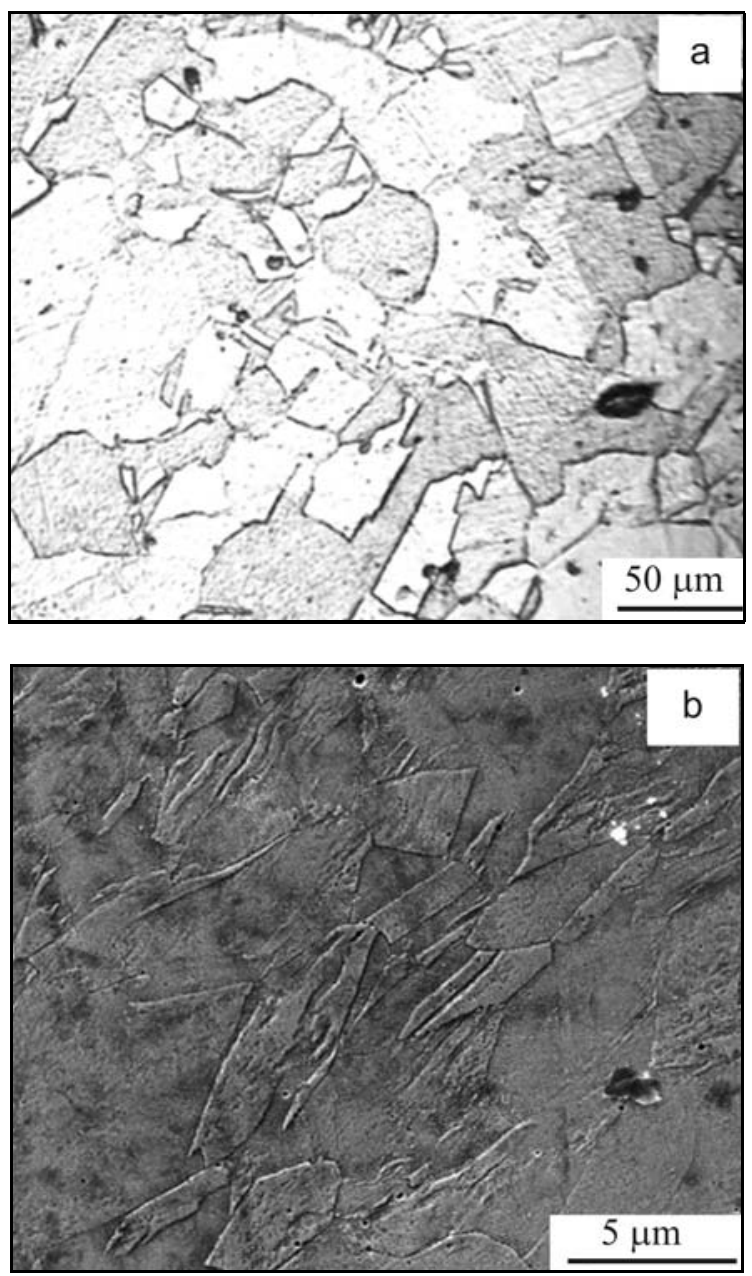

Fig. 8. Optical microscopy (a) and scanning electron microscopy (b) observations for the copper tube samples after three passes of equal channel angular pressing by route $\mathrm{C}$ using rubber pad mandrel.

ness distribution homogeneity, R-ECAP method is the most suitable process to fabricate tube materials when average hardness magnitude, average tube wall thickness and tube wall thickness tubularity are considered.

\subsection{Microstructure evaluation}

The annealed copper tube exhibits equiaxed grain size structure. Optical microscopy (OM) and scanning electron microscopy (SEM) were utilized to confirm the reduction of grain size for the annealed state sample and also, first and final passes of R-ECAPed copper tubes. Figure 8 represents OM and SEM observations before and after pressing of copper tubes after three passes using rubber pad method. The results indicate that there are about $38 \%$ and $85 \%$ reductions achieved for the first and third passes of RECAPed tubes with respect to un-ECAPed condition, respectively, according to ASTM E112. By considering this figure, UFG structure can be observed after three passes of pressing next to the relatively coarse grains.

\section{Conclusions}

In this research, tube shaped specimens were successfully ECAPed using three different techniques. Equal channel angular pressing die with the channel angle of $90^{\circ}$, outer corner of about $15^{\circ}$ and channel diameter of $19.1 \mathrm{~mm}$ were designed and manufactured. Commercial purity copper tubes have been pressed up to three passes by route $\mathrm{C}$ with the sand, rubber and grease materials as the mandrel (S-ECAP, R-ECAP and G-ECAP) to maintain tubularity of specimens. Hardness behavior and thickness variations of tube samples were investigated using Vickers micro hardness and tube thickness gauge measurements for both as-received and deformed conditions. The results indicate that about $(30 \%, 45 \%),(32 \%, 50 \%)$ and $(29 \%, 44 \%)$ enhancements have been achieved in the hardness magnitudes after first and third passes of $\mathrm{Cu}$ ECAPed tube samples with sand, rubber and grease mandrels, respectively; as compared to the unECAPed state. Furthermore, there is a loss of hardness distribution homogeneity as compared to the unECAPed state. Comparison of the three techniques indicates that the G-ECAPed tube attained the best uniform hardness distribution. In addition, tube wall thickness records reveal that equal channel angular pressing process with rubber pad method gives best wall thickness distribution uniformity. Finally, the results show that R-ECAPed tube process gives high hardness magnitude and uniform tube wall thickness as compared to S-ECAPed and G-ECAPed processes. More studies are required to investigate the influence of rubber pad properties on the both hardness characteristics and thickness variations of deformed samples.

\section{References}

[1] Valiev, R. Z., Islamgaliev, R. K., Alexandrov, I. V.: Prog. Mater. Sci., 45, 2000, p. 103. doi:10.1016/S0079-6425(99)00007-9 
[2] Song, R., Ponge, D., Raabe, D., Speer, J. G., Matlock, D. K.: Mater. Sci. Eng. A, 441, 2006, p. 1. doi:10.1016/j.msea.2006.08.095

[3] Popov, V. V., Popova, E. N., Stolbovskiy A. V.: Mater. Sci. Eng. A, 539, 2012, p. 22. doi:10.1016/j.msea.2011.12.082

[4] Valiev, R. Z., Langdon, T. G.: Prog. Mater. Sci., 51, 2006, p. 881. doi:10.1016/j.pmatsci.2006.02.003

[5] Pande, C. S., Cooper, K. P.: Prog. Mater. Sci., 54, 2009, p. 689. doi:10.1016/j.pmatsci.2009.03.008

[6] Furukawa, M., Iwahashi, Y., Horita, Z., Nemoto, M., Langdon, T. G.: Mater. Sci. Eng. A, 257, 1998, p. 328. doi:10.1016/S0921-5093(98)00750-3

[7] Beygelzimer, Y., Varyukhin, V., Synkov, S., Orlov, D.: Mater. Sci. Eng. A, 503, 2009, p. 14. doi:10.1016/j.msea.2007.12.055

[8] Saito, Y., Tsuji, N., Utsunomiya, H., Sakai, T., Hong, R. G.: Scr. Mater., 39, 1998, p. 1221. doi:10.1016/S1359-6462(98)00302-9

[9] Shin, D. H., Park, J. J., Kim, Y. S., Park, K. T.: Mater. Sci. Eng. A, 328, 2002, p. 98. doi:10.1016/S0921-5093(01)01665-3

[10] Furukawa, M., Iwahashi, Y., Horita, Z., Nemoto, M., Langdon, T. G.: Mater. Sci. Eng. A, 257, 1998, p. 328. doi:10.1016/S0921-5093(98)00750-3

[11] Segal, V. M.:. Mater. Sci. Eng. A, 197, 1995, p. 157. doi:10.1016/0921-5093(95)09705-8

[12] Raab, G. J., Valiev, R. Z., Lowe, T. C., Zhu, Y. T.: Mater. Sci. Eng. A, 382, 2004, p. 30. doi:10.1016/j.msea.2004.04.021
[13] Nagasekhar, A. V., Chakkingal, U., Venugopal, P.: J. Mater. Process. Technol., 173, 2006, p. 53. doi:10.1016/j.jmatprotec.2005.10.024

[14] Glaß, R., Hahn, F., Kolbe, M., Meyer, L.W.: J. Mater. Process. Technol., 80-81, 1998, p. 174. doi:10.1016/S0924-0136(98)00105-8

[15] Neugebauer, R., Glass, R., Kolbe, M., Hoffmann, M.: J. Mater. Process. Technol., 125-126, 2002, p. 856. doi:10.1016/S0924-0136(02)00392-8

[16] Toth, L. S., Arzaghi, M., Fundenberger, J. J., Beausir, B., Bouaziz, O., Massion, R. A.: Scr. Mater., 60, 2009, p. 175. doi:10.1016/j.scriptamat.2008.09.029

[17] Arzaghi, M., Fundenberger, J. J., Toth, L. S., Arruffat, R., Faure, L., Beausir, B., Sauvage, X.: Acta Mater., 60, 2012, p. 4393. doi:10.1016/j.actamat.2012.04.035

[18] Mohebbi, M. S., Akbarzadeh, A.: J. Mater. Process. Technol., 210, 2010, p. 510. doi:10.1016/j.jmatprotec.2009.10.014

[19] Mohebbi, M. S., Akbarzadeh, A.: Mater. Sci. Eng. A, 528, 2010, p. 180. doi:10.1016/j.msea.2010.08.081

[20] Zangiabadi, A., Kazeminezhad, M.: Mater. Sci. Eng. A, 528, 2011, p. 5066. doi:10.1016/j.msea.2011.03.012

[21] Faraji, G., Mashhadi, M. M., Kim, H. S.: Mater. Lett., 65, 2011, p. 3009. doi:10.1016/j.matlet.2011.06.039

[22] Nagasekhar, A. V., Chakkingal, U., Venugopal, P.: J. Manuf. Process., 8, 2006, p. 112. doi:10.1016/S1526-6125(06)80006-X

[23] Borhani, M., Djavanroodi, F.: Mater. Sci. Eng. A, 546, 2012, p. 1. doi:10.1016/j.msea.2012.02.089 